\title{
Safety and Efficacy of Coronary Stent Implantation. Acute and Six Month Outcomes of 1,126 Consecutive Patients Treated in 1996 and 1997
}

\author{
Luiz Alberto Mattos, Ibraim Pinto, Alexandre Abizaid, Andrea Abizaid, Aurea Chaves, Fausto Feres, \\ Galo Maldonado, Luiz Tanajura, Marinella Centemero, Amanda G. M. R. Sousa, J. Eduardo Sousa
}

São Paulo, SP - Brazil

\begin{abstract}
Purpose - The authors analyzed the 30-day and 6month outcomes of 1,126 consecutive patients who underwent coronary stent implantation in 1996 and 1997.

Methods - The 30-day results and 6-month angiographic follow-up were analyzed in patients treated with coronary stents in 1996 and 1997. All patients underwent coronary stenting with high-pressure implantation (>12 atm) and antiplatelet drug regimen (aspirin plus ticlopidine).
\end{abstract}

Results - During the study period, 1,390 coronary stents were implanted in 1,200 vessels of 1,126 patients; 477 patients were treated in the year 1996 and 649 in 1997. The number of percutaneous procedures performed using stents increased significantly in 1997 compared to $1996(64 \% \mathrm{vs}$ $48 \%, p=0.0001)$. The 30-day results were similar in both years; the success and stent thrombosis rates were equal (97\% and $0.8 \%$, respectively). The occurrence of new $Q$ wave MI (1.3\% vs 1.1\%, 1996 vs 1997, $p=N S)$, emergency coronary bypass surgery (1\% vs 0.6\%, 1996 vs 1997, $p=N S)$ and 30-day death rates (0.2\% vs 0.5\%, 1996 vs 1997, $p=N S)$ were similar. The 6-month restenosis rate was 25\% in 1996 and 27\% in $1997(p=N S)$; the target vessel revascularization rate was 15\% in 1996 and 16\% in 1997 ( $p=N S)$.

Conclusions - Intracoronary stenting showed a high success rate and a low incidence of 30-day occurrence of new major coronary events in both periods, despite the greater angiographic complexity of the patients treated with in 1997. These adverse variables did not have a negative influence at the 6-month clinical and angiographic follow-up, with similar rates of restenosis and ischemia-driven target lesion revascularization rates.

Keywords: stents, angioplasty, restenosis

Instituto Dante Pazzanese de Cardiologia - São Paulo - Brazil

Maling address: Luiz Alberto Mattos - Av. Jandira 550/121 - São Paulo, SP - Brazil
Coronary stent implantation has modified the treatment of patients with coronary artery disease who undergo percutaneous myocardial revascularization.

In December 1987, the first human coronary balloon expandable stent was implanted at the Instituto Dante Pazzanese de Cardiologia in São Paulo, Brazil. Since then, clinical and angiographic indications for this new percutaneous coronary revascularization method have expanded after many caveats have been refuted and the safety and efficacy required have been firmly established in clinical practice $^{1}$.

In the first years of its usage, randomized trials and many consecutive series of patients showed higher rates of thrombotic occlusion after coronary stent implantation ( 5 to $20 \%$ ). This adverse event stimulated the use of one of the most severe antithrombotic drug regimens ever applied in interventional cardiology in an attempt to reduce the incidence of this major coronary complication. However, the series of procedures that followed this pharmacological approach did not demonstrate a reduction in the subacute occlusion rates, and major bleeding, a serious side effect, occurred. It is natural to conclude that this approach resulted in longer hospital stays with increasing costs, making physicians leery of recommending this new percutaneous coronary revascularization method ${ }^{2-3}$.

The scenario changed, however, with the publication of the results of two major randomized studies in 1994, which compare balloon PTCA with stents. The comparison demonstrates that, stents can create significancy higher coronary lumen diameters, reduce the restenosis rate at the end of the first 6 months and as a consequence the need for further revascularization procedures, percutaneous or surgical, compared with the standard balloon PTCA method ${ }^{4-7}$. In 1995, Colombo et al ${ }^{8}$ demonstrated that intravascular ultrasound could optimize stent delivery and implantation, applying higher balloon pressures (>12 ATM), promoting better stent symmetry, with a nearly full 
apposition of the stent struts in the vessel wall. These benefits of stent geometry led the author to recommend the complete cessation of the old antithrombotic pharmacological regimen, introducing a new one, aimed at a more intensive antiplatelet blockage, with the combination of aspirin and ticlopidine. This new technique was called "optimal stent implantation" ${ }^{8-9}$.

The purpose of the present analysis is to verify in a consecutive series of patients who underwent coronary stent implantation at a single high-volume center, the impact of this new approach on clinical and angiographic outcomes at the acute and 6-month periods, comparing the results achieved in 1996 with those obtained in 1997.

\section{Methods}

For the current analysis, we selected all consecutive patients who underwent coronary stent implantation at our hospital from 01/1996 until 12/1997.

A specific pharmacological regimen was applied related to coronary stent implantation: in elective procedures, patients received aspirin (200mg PO) and ticlopidine (500mg PO), twenty-four hours before the implant. Thirty days after the index procedure, ticlopidine was stopped but aspirin was maintained indefinitely.

In nonelective stent implantation (acute myocardial infarction or after suboptimal results of balloon PTCA), aspirin and ticlopidine were started in the catheterization laboratory. Before the procedure, patients received a full dose of intravenous heparin (100 UI/kg).

Patients with successful procedures were discharged from the hospital 24 to 48 hours afterwards. The exception was patients with acute myocardial infarction who were usually discharged between day 5 and 7 after the acute event.

All patients treated during this period of time followed a protocol of serial lab analyses that included the dosage of CK-MB fraction prior to the procedure and 6 and 24 hours after it. New measurements were only required in cases of abnormal values (>10 UI). Routine ECGs was obtained before and immediately after the procedure, and before hospital discharge. On all clinical follow-up dates, a new ECG was performed.

The success of the procedure was defined as the ability to cross the target lesion and implant the stent, obtaining a residual stenosis of less than $50 \%$ by quantitative coronary angiography (QCA), with normal coronary flow (TIMI flow 3). Clinical success required the absence of the occurrence of any new major coronary event after the index procedure: new Q wave MI, urgent myocardial revascularization or death.

A new $Q$ wave MI was defined as the presence of typical chest pain for more than 30 minutes without relief after nitrate usage, ST segment elevation higher than $1 \mathrm{~mm}$ in more than one contiguous ECG lead and elevation of the CK-MB fraction twice that of the normal value (10 UI).
Urgent bypass surgery operation and death were verified in all patients at the end of the first month after the stent implantation.

The clinical follow-up protocol applied followed these rules: at day 30, the clinical success and occurrence of new major coronary events were checked; between day 30 and day 180 , at least one new clinical visit was required, prior to any new coronary angiography procedure. A new coronary angiography was routinely indicated in all patients even in asymptomatic ones. In patients without angina or with a negative functional test, coronary angiography was performed at the end of 180 days. Patients who presented with early recurrence of angina or positive functional tests underwent a new angiography as soon as possible.

Femoral access was the most common pathway for performing coronary angioplasty with stent implantation.

The stent procedure employed the QCA of the target coronary lesion performed after intracoronary administration of nitrates and followed these steps: a) Predilatation of the target lesion with conventional balloon PTCA, in the same size as the index reference diameter vessel or $0.5 \mathrm{~mm}$ less than this; b) Stent positioning in the coronary or graft segment desired, in order to cover the entire diseased segment; c) The stent (s) was (were) deployed with 8 to 12 ATM; d) Post-dilation with noncompliant balloons, with the same diameter size or until $1 \mathrm{~mm}$ higher than the index reference diameter vessel, inflated from 12 to 20 ATM; d) Measurement of the residual stenosis with QCA to obtain final stenosis smaller than $10 \%$.

The procedure endpoint was the obtainance of an optimal stent result defined as the absence of dissections at the stent edges, negative images suggestive of thrombus and severe peri-stent stenosis, plus the presence of a residual diameter stenosis $<10 \%$ with coronary TIMI 3 flow.

Routine intravascular ultrasound was not performed, being reserved for use only in the presence of nonoptimal stent procedural results, when the specified criteria above were not met.

The stent diameters employed ranged from 2.5 to $4.0 \mathrm{~mm}$, and lengths from 9 to $40 \mathrm{~mm}$. The stent chosen was based on the operator's discretion.

In the statistical analysis, continuous variables were verified with the Student $t$ test or by variance analysis, when the same sample sizes were tested. The categorical variables were analyzed by the chi-square test, with Fisher adjustment when necessary. All these tests used the Kwikstat computerized package and $p$ values less than 0.05 were considered statistically significant.

\section{Results}

During the period of this analysis, 1,390 coronary stents were implanted in 1,200 vessels of 1,126 patients. In 1996 and 1997, 477 and 649 patients were treated, respectively.

The clinical profile is displayed in table I, according to the year of the procedure (1996 or 1997). 


\begin{tabular}{|c|c|c|c|c|}
\hline Variables & 1996 & 1997 & $\mathrm{P}$ & Total \\
\hline Patients $\left(\mathrm{n}^{\mathrm{o}}\right)$ & 477 & 649 & & 1.126 \\
\hline Stents $\left(\mathrm{n}^{\mathrm{o}}\right)$ & 583 & 804 & 0.9 & 1.387 \\
\hline Stents per patient & 1,22 & 1.23 & 0.3 & 1.23 \\
\hline Male gender & $372(78 \%)$ & $477(74 \%)$ & 0.08 & $849(75 \%)$ \\
\hline Mean age (years) & $58.3 \pm 8$ & $58.4 \pm 9$ & 0.7 & $58.3 \pm 8$ \\
\hline Age $>70$ years & $74(16 \%)$ & $109(17 \%)$ & 0.6 & $183(16 \%)$ \\
\hline \multicolumn{5}{|l|}{ Coronary risk factors } \\
\hline Diabetics & $89(19 \%)$ & $125(19 \%)$ & 0.8 & $214(19 \%)$ \\
\hline Current smokers & $86(18 \%)$ & $139(21 \%)$ & 0.1 & $225(20 \%)$ \\
\hline Cholesterol $>200 \mathrm{mg} / \mathrm{dL}$ & $115(24 \%)$ & $122(19 \%)$ & 0.03 & $237(21 \%)$ \\
\hline \multicolumn{5}{|l|}{ Previous coronary events } \\
\hline Acute myocardial infarction & $76(16 \%)$ & $145(22 \%)$ & 0.01 & $221(20 \%)$ \\
\hline CABG & $94(20 \%)$ & $93(14 \%)$ & 0.02 & $187(17 \%)$ \\
\hline PTCA & $77(16 \%)$ & $114(17 \%)$ & 0.5 & $191(17 \%)$ \\
\hline Restenotic lesions & $29(6 \%)$ & $34(5 \%)$ & 0.6 & $63(5.5 \%)$ \\
\hline \multicolumn{5}{|l|}{ Clinical presentation } \\
\hline Stable angina & $202(42 \%)$ & $288(44 \%)$ & 0.5 & $490(44 \%)$ \\
\hline Unstable angina & $226(47 \%)$ & $287(44 \%)$ & 0.2 & $513(45.5 \%)$ \\
\hline Post intravenous thrombolysis & $29(6 \%)$ & $45(7 \%)$ & 0.6 & $74(6.5 \%)$ \\
\hline Primary PTCA & $20(5 \%)$ & $29(5 \%)$ & 0.9 & $49(4 \%)$ \\
\hline
\end{tabular}

We observed a significant increase in the usage of coronary stent procedures. In 1996, our hospital performed percutaneous coronary revascularizations in 976 patients and 477 (48\%) employed the stent technique, compared to 499 (52\%) that were treated with balloon PTCA. In 1997, the use of balloon PTCA only as a revascularization method was reduced to 371 patients (36\%) and the number of stents implanted increased to 649 patients $(64 \%)$, an absolute increase of $33 \%$ for coronary stenting $(\mathrm{p}=0.0001)$.

The clinical profile of the patients treated demonstrated the following statistical differences when the comparison between both years was performed. The proportion of patients with serum cholesterol levels $>200 \mathrm{mg} / \mathrm{dl}$ was lower in 1996 than in 1997, 24\% and 19\%, respectively; patients with previous bypass surgery decreased from $20 \%$ in 1996 to $14 \%$ in 1997. In contrast, the proportion of patients with previous MI increased from $16 \%$ in 1996 to $22 \%$ in 1997. All the other variables were similar in both periods of time, but we observed an excessive number of patients with acute coronary syndromes who underwent percutaneous revascularization with stents, nearly half of the entire group treated (58\% and 56\%, p=NS, 1996/97, respectively).

The angiographic profile for both years is demonstrated in table II. We observed a significant reduction in the number of venous bypass grafts treated from 1996 to 1997 (9.2\% vs $6.3 \%$, respectively) and also in lesions located in ostial segments (11\% vs $7 \%$, respectively). In 1997, the index reference diameter of the vessels treated decreased significantly (3.5mm vs 3.2mm, 1996 and 1997 respectively, $\mathrm{p}=0.0001$ ), which was demonstrated by QCA analysis (table III). The multivessel stent procedures increased by a significant proportion, accounting for $2.7 \%$ of $1996 \mathrm{vs} 9.2 \%$ of 1997 stent implants ( $\mathrm{p}=0.0001$ ).
The left ventricular function exhibited mean normal or small decreases in global ejection fraction in $86 \%$ of $1996 \mathrm{vs}$ $84 \%$ of 1997 patients ( $\mathrm{p}=\mathrm{NS}$ ).

Acute success and major complications did not demonstrate any statistical difference (table IV). The clinical success rates were high and similar in both periods of time $(97 \%)$. The occurrence of stent occlusion was rare, $0.8 \%$ for both years. The incidence of new $\mathrm{Q}$ wave MI was also similar, below $1.3 \%$. The need for urgent bypass surgery and the occurrence of death were uncommon, less than $1 \%$. The incidence of non-Q wave MI detected only by the presence the abnormal elevation of CK-MB fraction after the stent procedure was not analyzed.

Four deaths occurred in this series in the 30-day analysis, one in 1996 and three in 1997. The table V demonstrates the clinical profile, stent indication and cause of these deaths.

The results of QCA analysis are demonstrated in table III. The mean final balloon pressure after stent deployment was 17.9 \pm 3 ATM versus $16.3 \pm 2$ ATM, 1996 and 1997, respectively ( $\mathrm{p}=0.0001)$. The mean final diameter size of the balloon employed to optimize stent delivery was $3.48 \mathrm{~mm} \pm$ $0.4 \mathrm{~mm}$ versus $3.29 \pm 0.5 \mathrm{~mm}, 1996$ and 1997 , respectively $(\mathrm{p}=0.0001)$. The balloon vessel ratio was similar between these periods of time, 1.06 .

In 1996, 42 (9\%) patients exhibited lesion length greater than $20 \mathrm{~mm}$ and $31(7 \%)$ had index reference vessel diameter less than $3.0 \mathrm{~mm}$. These angiographic variables were modified in the 1997 analysis. The presence of lesion length greater than $20 \mathrm{~mm}$ was detected in 143 (22\%) of the patients treated, and in 87 (14\%) patients, small vessels with less than $3.0 \mathrm{~mm}$ of reference diameter $(\mathrm{p}=0.0001$ and $\mathrm{p}=0.0001,1996 / 97$, respectively) were detected. 


\begin{tabular}{|c|c|c|c|c|}
\hline Variables & 1996 & 1997 & $\mathrm{p}$ & Total \\
\hline Number of vessels treated & 491 & 709 & & 1.200 \\
\hline Left main & $4(0.8 \%)$ & $3(0.5 \%)$ & 0.6 & $7(0.6 \%)$ \\
\hline Left anterior descending & $216(45.3 \%)$ & $296(45.6 \%)$ & 0.4 & $512(43 \%)$ \\
\hline Circumflex & $87(18.2 \%)$ & $139(21.4 \%)$ & 0.4 & $226(19 \%)$ \\
\hline Right coronary & $137(29 \%)$ & $228(35 \%)$ & 0.1 & $365(30 \%)$ \\
\hline Saphenous venous grafts & $44(9.2 \%)$ & $41(6.3 \%)$ & 0.04 & $85(7 \%)$ \\
\hline Left internal mammary & $3(0.6 \%)$ & $2(0.3 \%)$ & 0.6 & $5(0.4 \%)$ \\
\hline \multicolumn{5}{|l|}{ Segment treated } \\
\hline Ostial & $55(11 \%)$ & $50(7 \%)$ & 0.01 & 105 \\
\hline Proximal & $283(58 \%)$ & $419(59 \%)$ & 0.6 & 702 \\
\hline Medial/distal & $153(31 \%)$ & $240(34 \%)$ & 0.3 & 393 \\
\hline \multicolumn{5}{|l|}{ Lesion type } \\
\hline $\mathrm{A}$ & $38(8 \%)$ & $40(6 \%)$ & 0.3 & $78(6.5 \%)$ \\
\hline B1 & $162(33 \%)$ & $257(36 \%)$ & 0.8 & $419(35 \%)$ \\
\hline B2 & $212(43 \%)$ & $288(41 \%)$ & 0.4 & $500(41.5 \%)$ \\
\hline $\mathrm{C}$ & $79(16 \%)$ & $124(17 \%)$ & 0.5 & $203(17 \%)$ \\
\hline \multicolumn{5}{|l|}{ Number of stents per patient } \\
\hline 1 Stent & $387(81 \%)$ & $520(80 \%)$ & 0.3 & $907(80.5 \%)$ \\
\hline 2 Stents & $77(16 \%)$ & $107(16.5 \%)$ & 0.4 & $184(16.3 \%)$ \\
\hline 3 Stents & $9(2 \%)$ & $18(2.8 \%)$ & 0.5 & $27(2.3 \%)$ \\
\hline 4 Stents & $3(0.6 \%)$ & $3(0.6 \%)$ & 0.2 & $6(0.5 \%)$ \\
\hline 5 Stents & $1(0.4 \%)$ & $1(0.1 \%)$ & 0.3 & $2(0.4 \%)$ \\
\hline
\end{tabular}

The mean hospital stay was $2.81 \pm 2$ days in 1996 decreasing to $2.33 \pm 3$ days in $1997(\mathrm{p}=0.001)$.

At the end of the 6-month follow-up, a higher number of patients treated in 1996 had undergone a new coronary angiography compared to patients in 1997 (53\% versus $38 \%, \mathrm{p}=0.0001)$. The mean time between the index procedure and the new angiography was $154 \pm 125$ days, for both years.

The recurrence of angina symptoms was detected in $45 \%$ of the patients treated in 1996 versus $57 \%$ of 1997 , and the occurrence of AMI was $1.6 \%$ in 1996 versus $0.8 \%$ in 1997 ( $\mathrm{p}=\mathrm{NS}$ ).

Coronary stent restenosis by binary definition were demonstrated in 62 (25\%) of the 1996 patients versus 66 $(27 \%)$ of 1997 patients $(\mathrm{p}=\mathrm{NS})$. The need for further revascularization procedures for the treatment of the target lesion, either percutaneous or surgical procedures, was si- milar in both periods of time, $37(15 \%)$ and $39(16 \%)$ patients in 1996/97, respectively ( $\mathrm{p}=\mathrm{NS}$ ).

The late follow-up QCA analysis revealed some statistical differences. The mean diameter stenosis was greater in 1997 than in $1996(36.4 \pm 22 \%$ versus $30.2 \pm 20.7 \%$, respectively, $\mathrm{p}=0.001$ ). The late lumen loss was higher in the 1996 period, $1.2 \mathrm{~mm}$, decreasing to $1.1 \mathrm{~m}$ in 1997 ( $\mathrm{p}=0.0001$ ).

\section{Discussion}

The results presented here demonstrate the high rate of efficacy and safety currently associated with percutaneous coronary stent implantation.

In 1997, we observed a significant increase in the angiographic complexity in patients who underwent coronary stent implantation in our hospital. The number of multivessel coronary stenting procedures increased from $2.7 \%$ to

\begin{tabular}{|c|c|c|c|}
\hline Variables/mean values & 1996 & 1997 & $\mathrm{p}$ \\
\hline \multicolumn{4}{|l|}{ Pre Stent } \\
\hline Reference diameter $(\mathrm{mm})$ & $3.2 \pm 0.4$ & $3.1 \pm 0.4$ & 0.0001 \\
\hline Minimal lumen diameter $(\mathrm{mm})$ & $0.8 \pm 0.4$ & $0.8 \pm 0.4$ & 0.1 \\
\hline Stenosis diameter $(\%)$ & $75.1 \pm 10.7$ & $75.4 \pm 102$ & 0.6 \\
\hline Lesion lenght $(\mathrm{mm})$ & $16 \pm 8.6$ & $18 \pm 7.7$ & 0.001 \\
\hline \multicolumn{4}{|l|}{ Post stent } \\
\hline Reference diameter $(\mathrm{mm})$ & $3.5 \pm 0.4$ & $3.2 \pm 0.4$ & 0.0001 \\
\hline Minimal lumen diameter $(\mathrm{mm})$ & $3.2 \pm 0.5$ & $3.1 \pm 0.6$ & 0.003 \\
\hline Stenosis diameter $(\%)$ & $4.5 \pm 8.2$ & $3.7 \pm 6.1$ & 0.06 \\
\hline Acute gain (mm) & $2.4 \pm 1$ & $2.3 \pm 0.8$ & 0.5 \\
\hline
\end{tabular}




\begin{tabular}{|c|c|c|c|c|}
\hline Variables & 1996 & 1997 & $\mathrm{P}$ & Total \\
\hline Clinical success & $461(97 \%)$ & $633(97 \%)$ & 0.4 & $1094(97 \%)$ \\
\hline Acute occlusion $(<24 \mathrm{~h})$ & $1(0.2 \%)$ & $3(0.5 \%)$ & 0.8 & $4(0.3 \%)$ \\
\hline Subacute occlusion $(>24 \mathrm{~h})$ & $3(0.6 \%)$ & $2(0.3 \%)$ & 0.7 & $5(0.4 \%)$ \\
\hline New $\mathrm{Q}$ wave MI & $6(1.3 \%)$ & $7(1.1 \%)$ & 0.9 & $13(1.1 \%)$ \\
\hline Urgent bypass surgery & $5(1 \%)$ & $4(0.6 \%)$ & 0.6 & $9(0.7 \%)$ \\
\hline Death (30 days) & $1(0.2 \%)$ & $3(0.5 \%)$ & 0.8 & $4(0.3 \%)$ \\
\hline
\end{tabular}

$9.2 \%, 1996 / 97$, respectively $(\mathrm{p}=0.0001)$ and twice as many patients with the target lesions located in small vessels $(<3.0 \mathrm{~mm})$ were treated with stents, $7 \%$ to $14 \%, 1996 / 97$, respectively $(\mathrm{p}=0.0001)$. In the same fashion, long lesions $(>20 \mathrm{~mm})$ more often were treated with stenting in 1997 compared to 1996 ( $22 \%$ vs $9 \%, \mathrm{p}=0.0001)$.

In contrast, the number of saphenous venous graft lesions treated with coronary stenting was reduced in 1997 compared to 1996 as the lesions located in ostial segments.

However, these were the only variables that did not have a significant increase during 1997 and were usually associated with more severe complexity. This finding did not reduce the impact of treating many more patients with multivessel coronary disease, located in small vessels and with tandem lesions.

The predictable results offered with stent implantation justify their increased usage in 1997, in an absolute order of $33 \%$ compared to 1996 . The analysis of the acute procedural and major coronary complication rates obtained with stents demonstrates better results than those ever reached with balloon PTCA. These results become more pronounced when associated with the increasing angiographic complexity observed here in this series. The acute success rates were high in both years $(97 \%)$ with a low rate of subacute occlusion $(<1 \%)$. The death rate at the end of 30 days was also low $(<0.5 \%)$. The low rate of mortality becomes more impressive when related to the fact that more than $50 \%$ of the patients were treated in the setting of an acute coronary syndrome. The need for urgent bypass surgery was also reduced from $1 \%$ in 1996 to $0.6 \%$ in 1997. The need for urgent surgical revascularization is becoming rare after percutaneous procedures that employ the stent technique. The incidence of new $\mathrm{Q}$ wave MI was lower than
$1 \%$ and, it is in accordance with the results from the major randomized trials recently published ${ }^{7-10}$.

Four deaths occurred in the first 30 days after the procedure, but only one was related to stent thrombosis, confirming the safety of coronary stenting, employing the optimal stent implantation technique and antiplatelet pharmacological regimen.

These optimal results obtained in a large random consecutive series of patients confirms the great technological development related to coronary stent usage, new adjunctive pharmacological measures and the operator's experience.

It is important to emphasize the need for a continuous search for a perfect angiographic outcome after stent deployment. This concept is called "optimal stent technique". Stents have the potential for equalizing all the clinical and angiographic complexities found in many different subgroups of patients suffering from coronary heart disease. However, it is important to plan the stent implantation in a meticulous way. We must choose the stent most suitable to cover the entire target lesion length and with enough flexibility to cross the curves that exist in coronary anatomy. Actually, more than 30 different types of stents are available for clinical use in our country. So, the process starts with the correct interpretation of the coronary angiogram, selecting the target lesion/vessel to be treated percutaneously and the specific stent size and length needed. The major obstacles to stent delivery are the presence of massive calcification and excessive tortuosity. The correct assessment of these variables will determine the stent selected or may even contraindicate the procedure.

Success should be defined by adjunctive use of QCA analysis. The operator should seek for the lowest diameter

\begin{tabular}{|lcccc|}
\hline \multicolumn{4}{|c|}{ Table V - Clinical and procedural profile from the four 30 day deaths } \\
\hline Gender/Age & Clinical presentation & Stent indication & Procedural result & Death \\
\hline 1) Male, 62 years & Post MI angina & Elective & Success & Sudden death (24 hours) \\
2) Male, 60 years & Stable angina & Non elective & Failure deliver to stent & Urgent CABG + MI (18 d) \\
3) Female, 68 years & Post MI angina & Elective & Success & Sepsis (24 d) \\
4) Female, 76 years & Unstable angina & Elective & Success & Sub acute occlusion + MI (7 d) \\
\hline MI - myocardial infarction & & & & \\
\hline
\end{tabular}


stenosis without dissections, uncover diseased segments and thrombus formation. The complementary safety measure is related to the prescription of antiplatelet pharmacological regimen (aspirin plus ticlopidine) maintained for at least 30 days.

At the end of the 6-month follow-up period different rates of new coronary angiographies were observed between the comparison of both years, but this accounts for less than $60 \%$ of the whole group initially treated with stents. In addition, more than half of the patients had recurrent angina before the follow-up angiography. However, even in the presence of these adverse variables, the restenosis rate was lower than $30 \%$ and similar between both years $(25 \%$ and $27 \%, \mathrm{p}=\mathrm{NS})$.

The need of ischemia-driven new revascularization procedures for the target stent lesion (s) was also similar in both years here analyzed, $16 \%$ and 15\%, 1996/97, respectively ( $\mathrm{p}=\mathrm{NS}$ ).

The evidence obtained at the end of the 6-month outcome period demonstrated that even with the inclusion and treatment of more significant adverse variables noted on angiography in 1997 (small vessels, long lesions and multivessel procedures), did not increase the restenosis rate and the ischemia-driven target lesion revascularization rates.

The randomized study BENESTENT II ${ }^{7}$ compared the implant of heparin coated Palmaz-Schatz stents with balloon PTCA in 827 patients; with stable and unstable angina. This clinical trial demonstrated better results in patients treated with stents, with a low rate of acute major events (1.2\%) and with only $0.2 \%$ of sub/acute occlusion rate related to stent thrombosis. The restenosis was $16 \%$ for coronary stenting versus $31 \%$ in balloon PTCA patients ( $\mathrm{p}=0.0008$ ).

Many other interventional trials have tested coronary stents in different clinical and angiographic settings. The majority of these trials report favorable outcomes with stenting. Coronary stents have been shown to be superior in terms of better hospital results with a lower incidence of new major coronary events, offering the lowest residual diameter stenosis ever obtained in interventional cardiology and promoting a positive and quantitative influence toward lower restenosis and new target vessel revascularization rates. This outcome was observed in vein grafts $(\text { SAVED })^{11}$, restenotic lesions (REST) ${ }^{12}$, chronic occlusions $\left(\mathrm{SICCO}^{13}\right.$ and GISSOC ${ }^{14}$ ) and in the first twenty-four hours of AMI (Zwole ${ }^{15}$, FRESCO ${ }^{16}$ and PAMI Stent ${ }^{17-19}$ ).

The significant knowledge gained from the use of stent techniques and the interaction of stents with the vessel wall led to the employment of slightly lower pressures in 1997 without affecting the acute results. The lower lumen loss observed in 1997 might be related to this measure. However, researchers should be cautious of this conclusion because further evidence is needed from intravascular ultrasound and histological studies.

The optimization of the stent technique and the use of antiplatelet drugs (aspirin + ticlopidine) ${ }^{2-3}$ led to a reduction in the mean hospital stay in 1997 compared to 1996 ( 2.3 days versus 2.8 days, respectively, $\mathrm{p}=0.0001$ ).

In current interventional cardiology practice, stenting is the main percutaneous technique used. Stents offer a predictable result and have become the great equalizer in the face of many different clinical and angiographic characteristics. The results from a consecutive series of patients like ours and randomized trials confirm the superiority of stents to balloon PTCA, both in the hospital and late followup outcomes. In the presence of some high-risk subgroups of patients, such as those with diabetes ${ }^{20-21}$, unstable angina $^{7}$, acute myocardial infarction ${ }^{15-19}$, vessels with reference size $<3.0 \mathrm{~mm}^{7}$, balloon PTCA failures ${ }^{6}$, lesions located in he proximal left anterior descending artery ${ }^{7,22}$, chronic occlusions ${ }^{13-14}$, vein grafts ${ }^{11}$, restenotic lesions ${ }^{12}$ and multivessel coronary disease ${ }^{23}$, who undergo percutaneous coronary revascularization, stents will promote better results and should be the technique of first choice.

\section{References}

1. Mattos L, Chaves A, Feres F, et al. Optimal coronary stent implantation wihtout ultrasound guidance withholding subsequent anticoagulation. Can it be done safely? J Invas Cardiol 1995; 7: 10A.

2. Schomig A, Neumann FJ, Kastrati A, et al. A randomized comparison of antiplatelet and anticoagulation therapy after the placement of coronary artery stents. N Eng J Med 1996; 334: 1084-9.

3. Leon MB, Baim DS, Popma JJ, et al. A clinical trial comparing three antithromboticdrug regimens after coronary - artery stenting. N Engl J Med 1998; 339: 1665-71.

4. Serruys PW, de Jaegere P, Kiemeneij F, et al. A comparison of balloon expandable stent implantation with balloon angioplasty in patients with coronary artery disease. N Engl J Med 1994; 331: 489-95.

5. Fischman Dl, Leon MB, Baim DS, et al. A randomized comparison of coronary stent placement and balloon angioplasty in the treatment of coronary artery disease. N Engl J Med 1994; 331: 496-501.

6. Roubin GS, Cannon AD, Agrawal SK, et al. Intracoronary stenting for acute and threatenead closure complicating percutaneous transluminal coronary angioplasty. Circulation 1992; 85: 916-27.
7. Serruys PW, Van Hout B, Bonnier H, et al. Randomized comparison of implantation of Heparin coated stents with balloon angioplasty in selected patients with coronary artery disease (BENESTENT-II). Lancet 1998; 352: 673-81.

8. Colombo A, Hall P, Nakamura S, et al. Intracoronary stenting without anticoagulation accomplished with ultrasound guidance. Circulation 1995; 91: 1676-88.

9. Albiero R, Rau T, Schluter M, et al. Comparison of immediate and intermediate term results of intravascular ultrasound versus angiography-guided Palmaz Schatz stent implantation on matched lesions. Circulation 1997; 96: 2997-3005.

10. The EPISTENT Investigators. Randomized placebo-controlled and balloon angioplasty controlled trial to assess safety of coronary stenting with use of platelet glycoprotein IIb/IIIa blockade. Lancet 1998; 352: 87-92.

11. Savage MP, Douglas JS, Fischman DL, et al. For the Saphenous Vein de Novo Trial investigators. Stent placement compared with balloon angioplasty for obstructed coronary bypass grafts. N Engl J Med 1997; 337: 740-7.

12. Erbel R, Haude M, Hopp HW, et al. Coronary - artery stenting compared with balloon angioplasty for restenosis after initial balloon angioplasty. N Engl J Med 1998; 339: 1672-8. 
13. Sirnes PA, Golf S, Myreng Y, et al. Stenting in chronic coronary occlusion (SICCO): a randomized, controlled trial of adding stent implantation after successful angioplasty. J Am Coll Cardiol 1996; 28: 1144-51.

14. Rubartelli P, Niccoli L, Verna E, et al. Stent implantation versus balloon angioplasty in chronic coronary occlusions: results from the GISSOC trial. J Am Coll Cardiol 1998; 32: 90-6.

15. Suryapranata H, Vanthof AMJ, Hoorneje JCA, et al. Randomized comparison of coronary stenting with balloon angioplasty in selected patients with acute myocardial infarction. Circulation 1998; 97: 2502-5.

16. Antoniucci D, Santoro G, Bolognese L, et al. A clinical trial comparing primary stenting of the infarct related artery with optimal primary angioplasty for acute myocardial infarction. J Am Coll Cardiol 1998; 31: 1234-9.

17. Stone G, Brodie B, Griffin J, et al. Prospective, multicenter study of the safety and feasibility of primary stenting in acute myocardial infarction: In-hospital results and 30 day results of the PAMI Stent Pilot Trial. J Am Coll Cardiol 1998; 31: 23-30.

18. Serruys PW, Grines CL, Stone GW, et al. Stent implantation in acute myocardial infarction using a heparin coated stent. A pilot study as a preamble to a randomized trial comparing balloon angioplasty and stenting. Int J Cardiovasc Interventions 1998; 1: 19-27.

19. Grines CL, Cox D, Garcia E, et al. Stent PAMI: Primary endpoint rsults of a multicenter randomized trial of heparin coated stenting vs. primary PTCA for AMI. Circulation 1998; 98: I-22.

20. Abizaid A, Kornowski R, Mintz GS, et al. The influence of diabete mellitus on acute and late clinical outcomes following coronary stent implantation. J Am Coll Cardiol 1998; 32: 584-9.

21. Van Belle E, Bauters C, Hubert E, et al. Restenosis rates in diabetic patients : A comparison of coronary stenting and balloon angioplasty in native coronary vessels. Circulation 1997; 96: 1454-60.

22. Versaci F, Gaspardone A, Tomai F, et al. A comparison of coronary artery stenting with angioplasty for isolated stenosis of the proximal left anterior descending coronary artery. N Engl J Med 1996; 336: 817-22.

23. Moussa I, Reimers B, Moses J, et al. Long term angiographic and clinical outcome of patients undergoing multivessel coronary stenting. Circulation 1997; 96: 3873-9. 